\title{
Slope stability analysis under rainfall conditions considering unsaturated characteristics of materials
}

\author{
Sha Wang ${ }^{1, *}$, Guodong $\mathrm{Mei}^{1}$, Xuyang Xie ${ }^{1}$, Li Yaoxuan ${ }^{1}$, Lu Yao ${ }^{1}$ \\ ${ }^{1}$ Beijing General Research Institute of Mining \& Metallurgy
}

\begin{abstract}
As one of the important facilities in mines, the dump has become one of the major hidden dangers of mine safety management due to its large volume and loose structure. In this paper, based on unsaturated seepage theory of soil and practical engineering slope cases, the slope stability calculation model based on Bishop limit equilibrium method is established. This paper analyzes and calculates the evolution law of slope stability under extreme rainfall, obtains the law of slope stability safety coefficient changing with rainfall under unsaturated characteristics, and puts forward the corresponding countermeasures.
\end{abstract}

\section{Research background}

Non-ferrous metal dumping sites are used for centralized stacking of wastes discharged from mining, which are large in volume and loose in structure, resulting in serious safety problems [1][2], especially in the southern region, where there is abundant and concentrated rain [3]. The results show that the shear strength of the material in the dump is reduced by the action of water. Furthermore, the stability of the loose reactor is adversely affected by the vertical upward buoyancy force.

In order to study the effect of heavy rainfall on the slope stability under the action of unsaturated characteristics, a slope stability calculation model is established according to the accumulation characteristics of actual engineering, unsaturated characteristics of materials and local rainfall data, and the slope stability under the action of heavy rainfall is studied.

\section{Limit equilibrium method: Bishop method}

Bishop method is one of the slices methods. It is assumed that the sliding surface is a circular surface, the force on the side of the soil strip is taken into account, and the anti-slip safety coefficient of the bottom sliding surface of each soil strip is assumed to be the same, that is, equal to the average safety coefficient of the whole moving surface [4][5]. This method is also a method for dam slope stability analysis that meets all the torque equilibrium conditions and does not meet the horizontal force equilibrium.

\section{Safety factor analysis of slope stability}

\subsection{Calculation model and parameters}

Representative calculated sections and material partitions are selected, as shown in Fig. 1. The physical and mechanical parameters of the dump accumulation body and the original stratum are selected as shown in Table 1. The annual average rainfall is about $1650 \mathrm{~mm}$, the maximum rainfall is $2500 \mathrm{~mm}$, the minimum rainfall is $1050 \mathrm{~mm}$, and the maximum daily rainfall is $240 \mathrm{~mm}$. It is assumed that the extreme rainfall condition is: daily rainfall is $250 \mathrm{~mm}$ and continuous rainfall is 10 days. The initial condition of the infiltration line is the steady seepage state infiltration line under the natural condition, which simulates the slope stability change process under the condition of gradual rainfall infiltration.

\footnotetext{
*Corresponding author: wangsha@bgrimm.com
} 


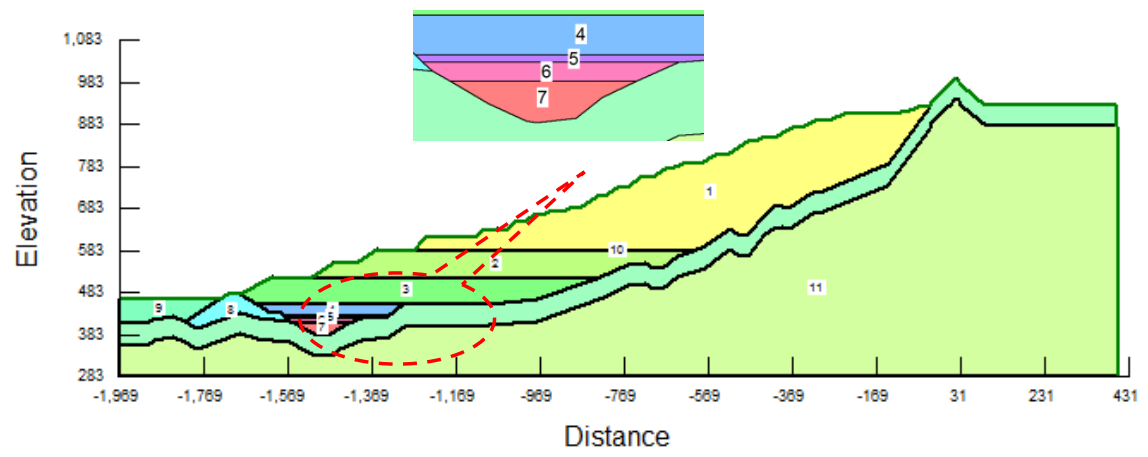

Fig. 1. Slope calculation section material partition

Table 1 Stability calculation parameters of Beikou dump

\begin{tabular}{|c|c|c|c|c|c|}
\hline Number & Name & $\begin{array}{c}\text { Unit } \\
\text { Weight } \\
\left(\mathrm{kN} / \mathrm{m}^{3}\right)\end{array}$ & $\begin{array}{l}\text { Cohesion } \\
\mathrm{c}(\mathrm{kPa})\end{array}$ & $\begin{array}{l}\text { Friction } \\
\text { Angle }\left(^{\circ}\right)\end{array}$ & $\begin{array}{l}\text { Permeability } \\
\text { Coefficient } \\
\mathrm{k}(\mathrm{cm} / \mathrm{s})\end{array}$ \\
\hline 1 & Soil Material 1 & 19.7 & 21.0 & 27.0 & $2.0 \times 10^{-2}$ \\
\hline 2 & Soil Material 2 & 19.5 & 18.0 & 23.0 & $2.0 \times 10^{-2}$ \\
\hline 3 & Soil Material 3 & 19.0 & 15.0 & 21.0 & $1.5 \times 10^{-3}$ \\
\hline 4 & Sand Gravel & 18.3 & 11.2 & 23 & $7.8 \times 10^{-4}$ \\
\hline 5 & Coarse Sand & 19.0 & 15.0 & 23 & $5.8 \times 10^{-4}$ \\
\hline 6 & Breccia Sand Gravel & 17.9 & 10.0 & 25 & $6.7 \times 10^{-4}$ \\
\hline 7 & Crushed Stone & 17.4 & 9.0 & 24.6 & $9.3 \times 10^{-4}$ \\
\hline 8 & Alluvial Clay Layer & 20.0 & 32.0 & 20 & $2.0 \times 10^{-5}$ \\
\hline 9 & Golden Slag Material & 19.5 & 20 & 22 & $1.5 \times 10^{-3}$ \\
\hline 10 & $\begin{array}{l}\text { Sand-like Strongly Weathered } \\
\text { phyllite }\end{array}$ & 21.0 & 30.0 & 35.0 & $4.2 \times 10^{-4}$ \\
\hline 11 & Moderately Weathered phyllite & 26.0 & 200.0 & 41.0 & $5.0 \times 10^{-6}$ \\
\hline
\end{tabular}

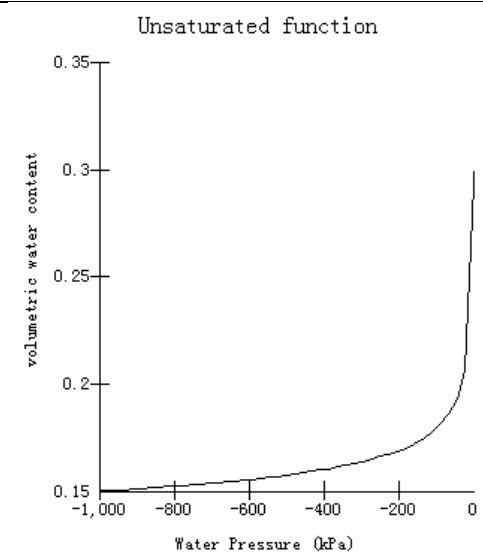

Fig.2 Relationship curve between volumetric moisture content and negative pressure head 

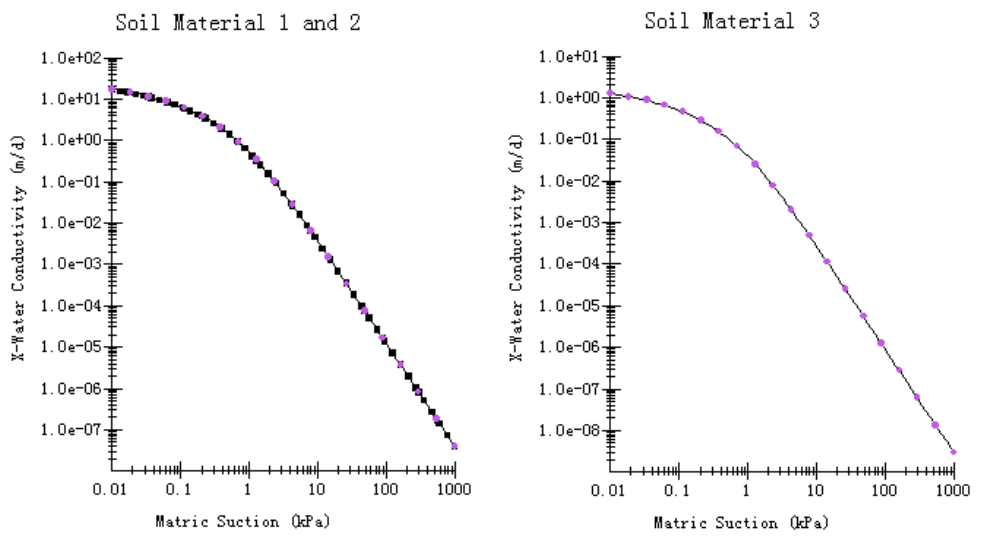

(a) Soil material 1 and 2 (b) Soil material 3

Fig. 3 relationship curve between matric suction and permeability coefficient

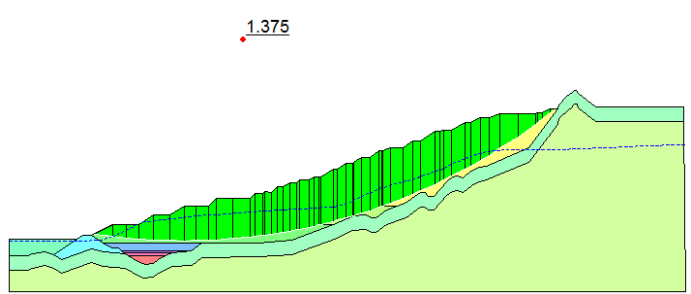

Time: $0 \mathrm{~d}$

.1 .326

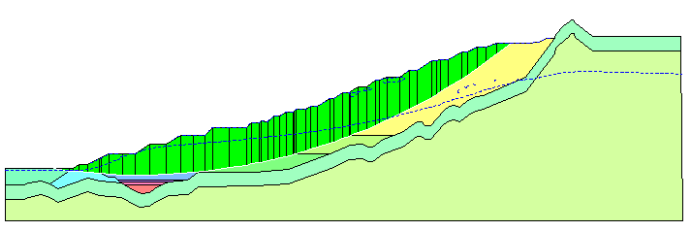

Time: $4 \mathrm{~d}$

.1 .298

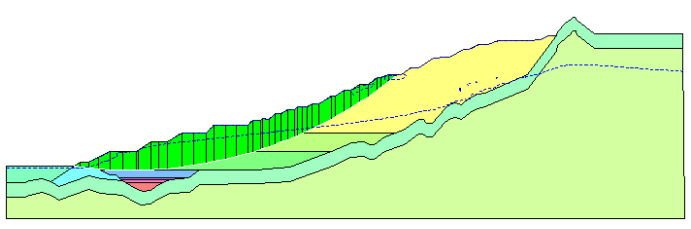

Time: $8 \mathrm{~d}$

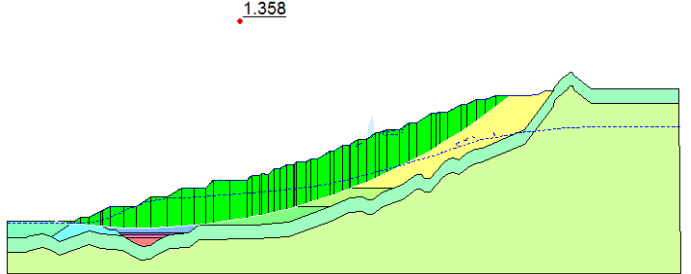

Time: $2 \mathrm{~d}$

.1 .312

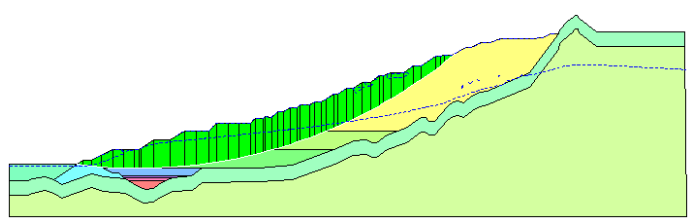

Time: $6 \mathrm{~d}$

.1 .284

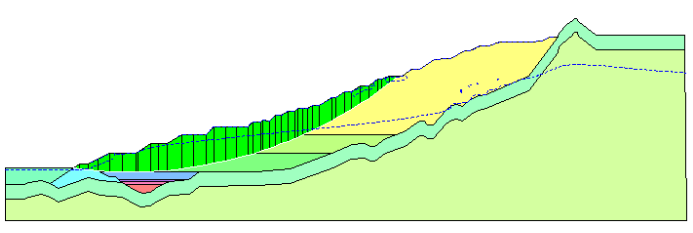

Time: 10d

Fig. 4 slope stability change process under rainfall condition

The relationship between the volumetric moisture content of soil material $1 \sim 3$ and the negative pore water pressure is shown in figure 2 . With the increase of negative pore water pressure, the volume moisture content of soil increases. The relationship between permeability coefficient of soil material $1 \sim 3$ and matric suction under unsaturated condition is shown in figure 3 . The permeability coefficient decreases with the increase of matric suction.

\subsection{Calculation results of safety factor}

Under extreme rainfall conditions, see figure 4 for the minimum safety factor of the slope stability and the corresponding sliding arc evolution process. According to the calculation results, with the increase of rainfall duration, the overall location of the most dangerous sliding arc gradually decreases, which is related to the gradual increase of rainfall leading to local saturation area on the surface, although the rainfall seeps down along the underlying surface, leading to the increase of the subsurface water level.

The safety factor evolution of a single sliding arc is shown in figure 5. The results show that the safety coefficient of the specified arc decreases with the increase of rainfall duration, and the safety coefficient is negatively correlated with rainfall duration. 


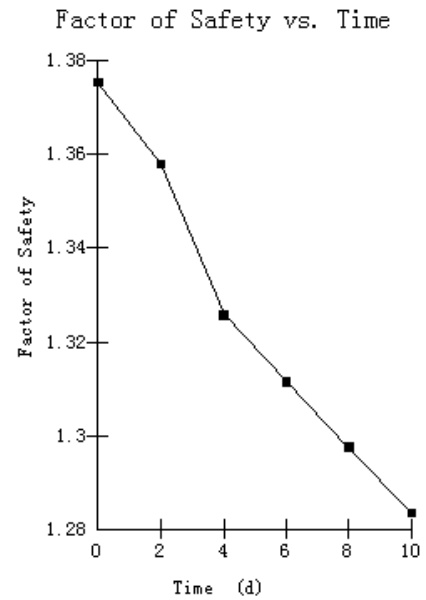

Fig. 5 variation of safety factor with the change of rainfall time

\section{Conclusion}

According to the unsaturated characteristics of soil in the dump, the slope stability calculation model under extreme rainfall is established, the relationship between slope stability and rainfall length was studied, and the relationship between the most dangerous arc and rainfall time was obtained. At the same time, the evolution law of the safety factor of a particular sliding arc with the duration of rainfall is obtained, and the following conclusions and suggestions are obtained:

(1)With the increase of continuous rainfall time, the infiltration line in the dump gradually rises. At the same time, on the surface of the slope body, the saturated area appeared locally, and the saturated area gradually increased with the increase of rainfall duration.

(2)The location of the most dangerous sliding arc in the dump gradually moves down along the sliding surface, indicating that the potential sliding body gradually moves down to the foot of the slope. At this point, the size of the foot cover will have a favorable effect on the slope stability. In order to reduce the adverse effect of rainfall, it is recommended to use materials with greater shear strength at the foot of the slope of the dump, whose volume size matches the size of the dump.

(3)The safety factor of specified arc decreases with the increase of rainfall time, and the two are negatively correlated. This is related to the elevation of infiltration line caused by rainfall. The calculation results of infiltration line show that the saturation degree of soil at the slope foot is high. Based on this, it is suggested to adopt effective drainage facilities at the slope foot to reduce the excessive infiltration line at the slope foot caused by rainfall.

\section{Acknowledgments}

This research was funded by the National Key R\&D Program of China (No.2018YFC0604605).

\section{References}

1. HE Y. H.. Numerical Simulation on Dump Slope Stability under Rainfall Infiltration[J]. Journal of Yangtze River Scientific Research Institute, 2015, 32(2):44-47.

2. GAN H.K., ZHOU H.M., CUI X., QIE Y..Stability analysis of multi-stage dump slope under long time rainfall infiltration[J]. Nonferrous Metals (Mining Section), 2014, 66(05):79-84.

3. Huang G.H..Stability analysis of waste dump with complex terrain under heavy rainfall infitration[J]. Chinese Journal of Geotechnical Engineering, 2013,35(S2):292-295.

4. ZHOU Z.B.. Study of Slope Stability Based on Limit Equilibrium Method \& Finite Element Method[D]. Hohai University, 2003.

5. CHEN Z.Y., MI H.L.,WANG X.G.. A three-dimensional limit equilibrium method for slope stability analysis[J]. Chinese Journal of Geotechnical Engineering, 2001, 23(5):525-529. 